\title{
Investigação Temática Freireana e o Ensino de Ciências no Assentamento Nova Santo Inácio Ranchinho
}

\author{
Freirean Thematic Investigation and Science Teaching in the Nova Santo \\ Inácio Ranchinho Settlement
}

\author{
Vitória Costa de Assis (vitoriaassis95@outlook.com) \\ Universidade Federal do Triângulo Mineiro - UFTM \\ Laís de Souza Rédua (lais.redua@hotmail.com) \\ Universidade Estadual de Minas Gerais - UEMG \\ Danilo Seithi Kato (danilo.kato@uftm.edu.br) \\ Universidade Federal do Triângulo Mineiro - UFTM
}

\begin{abstract}
Resumo:Modelos educacionais utilizados atualmente seguem uma tendência de homogeneização cultural que desconsidera a diversidade étnica, territorial e cultural na qual os sujeitos estão inseridos. Nesse sentido, um trabalho de conclusão de curso se orientou a partir da seguinte questão: Quais contradições vividas e percebidas no contexto de uma escola do campo podem ser mobilizadas a partir do ensino de ciências? Sendo assim, o objetivo deste trabalho consiste em mobilizar a realidade de uma escola do campo do município de Campo Florido - MG com temas geradores que oportunizam uma educação crítica para o ensino de ciências e para uma leitura de mundo que consiga articular avanços frente às situações limites e contraditórias locais. Foi desenvolvido a partir dos princípios da pesquisa-ação, sendo adotado o modelo teórico-metodológico da investigação temática freireana para construção de quatro ações pedagógicas das quais participaram alunas e alunos da Educação para Jovens e Adultos - EJA da escola localizada no assentamento Nova Santo Inácio Ranchinho e que atende à comunidade. A dialogicidade imbricada no processo suscitou discussões acerca dos modelos de produção, memórias dos assentados e desafios vivenciados pela comunidade. Os conflitos socioambientais surgiram como temas geradores, acentuados principalmente pela disputa pelo território, que inclui não somente a propriedade da terra, mas as relações com a natureza, culturais e de trabalho desenvolvidas pela comunidade configurando uma situação limite. A construção de processos educativos para o ensino de ciências pelas relações estabelecidas na comunidade aponta a memória biocultural dos assentados e assentadas fundamental para articular estes elementos em contraponto ao currículo alinhado com a lógica de grandes transnacionais de commodidities.
\end{abstract}

Palavras-chave: Educação do Campo; Escola do Campo; Ensino de Ciências.

Abstract: Educational models used today follow a trend of cultural homogenization that disregards the ethnic, territorial and cultural diversity in which the subjects are inserted. In this sense, a course conclusion work was guided by the following question: What contradictions experienced and perceived in the context of a rural school can be mobilized from science teaching? Therefore, the objective of this work is to mobilize the reality of a rural school in the municipality of Campo Florido - MG with generative themes that provide critical education for science teaching and for a world reading that can articulate advances in the face of situations local limits and contradictions. It was 
developed based on the principles of action research, adopting the theoreticalmethodological model of Freire's thematic research to build four pedagogical actions in which students from the Youth and Adult Education - EJA of the school located in the Nova Santo Inácio settlement Ranchinho and that serves the community. The dialogicity interwoven in the process led to discussions about production models, memories of settlers and challenges experienced by the community. Socioenvironmental conflicts emerged as generating themes, accentuated mainly by the dispute over the territory, which includes not only land ownership, but the relationships with nature, cultural and work developed by the community, configuring a limit situation. The construction of educational processes for the teaching of sciences by the relationships established in the community points to the biocultural memory of the settlers and settlers essential to articulate these elements in contrast to the curriculum aligned with the logic of large commodity transnationals.

Keywords: Countryside Education; School of the field; Science teaching

\section{INTRODUÇÃO}

Os processos de ensino e de aprendizagem que são desenvolvidos na escola envolvem uma série de aspectos que os constituem em uma profunda complexidade. Contudo, muitas das metodologias de ensino adotadas tendem a reforçar uma compreensão estática, minimizando a dinâmica que rege a vida, principalmente pensando as ciências da natureza (DELIZOICOV; ANGOTTI; PERNAMBUCO, 2009). Em contrapartida Freire (2015) pensa os processos educativos como permeados pela dialogicidade nos quais os educandos sejam além do sujeito em formação, mas também ativos neste processo desde a constituição do Projeto Político Pedagógico da escola até o currículo em desenvolvimento, visando uma educação libertadora.

Neste sentido o Freire (2015) oferece aporte teórico metodológico a partir da Investigação Temática (IT), uma perspectiva que parte da sistematização de eventos em constante reconstrução, mobilizada pela dialogicidade assumida pelo professor e alunos inseridos em determinada realidade. Por sua vez a dialogicidade se dá pelo encontro das falas e pela escuta dos sujeitos envolvidos no processo, de modo que nas palavras se movimentam e interpenetram interações formativas na alteridade e entendimento entre os diferentes. Ação e reflexão também são dimensões compreendidas na dialogicidade, que possibilita a compreensão de temas pela codificação e descodificação que mobilizam componentes curriculares fomentando a construção de conteúdos programáticos, desenvolvendo assim processos educacionais que respeitam o contexto 
histórico, social, cultural e econômico no qual os sujeitos se inserem, carregando de sentido a educação escolar (FREIRE, 2015).

Dessa maneira, pensando a educação do campo se faz necessária uma proposta que deixe de lado o modelo de imposição de saberes e cientificista, assumindo uma metodologia que tenha como temas geradores questões autóctones à realidade a que se destina, valorizando o sujeito como parte do processo de ensino aprendizagem e estabelecendo diálogos entre diferentes saberes, acolhe e propõe a manutenção de uma multiplicidade de culturas(DELIZOICOV; ANGOTTI; PERNAMBUCO, 2009). Silveira da Rosa e Robaina (2020) salientam a partir de um levantamento bibliográfico queo ensino de ciências na educação do campo se dá pela fragmentação em disciplinas baseadas na memorização, desconectado da realidade vivenciada pelo aluno e obedecendo a um currículo urbano, numa perspectiva conteudista e bancária (SILVEIRA DA ROSA; ROBAINA, 2020).Por isso, uma das propostas da educação do campo é efetivar o ensino escolar de modo que atenda as demandas do campo, de acordo com as atividades realizadas no e para o campo,assim como abordagens específicas que, a partir de sua história e localidade, diferem dos aspectos considerados para pensar o ensino em centros urbanos (RIBEIRO, 2008).

O ensino de ciências nos anos iniciais da escolarização, tem um papel fundamental no que diz respeito ao contato do aluno com o meio científico e é majoritariamente / baseado em Classificações e comparativos (DELIZOICOV; ANGOTTI; PERNAMBUCO, 2009). De acordo com a Base Nacional Comum Curricular - BNCC, as ciências da natureza no ensino fundamental têm uma função de letramento científico, de modo que o aluno consiga compreender e interpretar o mundo e transformá-lo com base no subsídio teórico e processual das ciências, alinhado à perspectiva restrita das habilidades e competências(BRASIL,2017).Nesse sentido, o currículo escolar chega de maneira radicalmente verticalizada, sendo estabelecido de maneira completamente exógena ao contexto da comunidade. Por isso, as questões locais deixam de ser o eixo central do processo de ensino e de aprendizagem, configurando um silenciamento de múltiplas identidades em nome de uma universalização colocada por um modelo curricular transnacional, desarticulado ao território, impactando diretamente no chão da sala principalmente de escolas do campo (BARBOSA; FERREIRA; KATO, 2020). 
A presente pesquisa, cuja abordagem colaborativa envolveu vivências de processos educativos em uma escola do campo orientando um trabalho de conclusão de curso, dados dessa construção compõe os aprofundamentos teóricos-metodológicos desse artigo. Esse processo de produção inclina-se na necessidade da reflexão acerca dos modelos educacionais utilizados atualmente, principalmente os que regem a escola do campo, que por suas particularidades demanda uma pedagogia que considere a relação com o território assim como os elementos sócio-histórico-culturais que atravessam a comunidade e as tensões identitárias que envolvem os sujeitos. A territorialidade então não se restringe apenas a dimensão geográfica, mas a oralidade, a relação com o trabalho e com a natureza, e as práticas desenvolvidas por essa comunidade. Nesse sentido, a educação é pensada a partir do local e suas particularidades, por isso a investigação temática.

Nesse sentido, o objetivo da pesquisa consiste em analisar o processo de investigação temática em uma escola do campo no Assentamento Nova Santo Inácio Ranchinho e a percepção das contradições vividas pelos sujeitos como princípio educativo para as ciências da natureza.

\section{METODOLOGIA}

A pesquisa foi desenvolvida baseada em uma abordagem qualitativa, considerando interpretações de experiências reais, sendo os pesquisadores imersos nessa realidade para investigar relações humanas,não estando desvinculados desse processo (OLIVEIRA, 2008). Dessa maneira, se apoiou na perspectiva Freireana da IT(FREIRE,2015) e na pesquisa-ação (TOLEDO; JACOBI,2013), para analisar construções de processos de ensino aprendizagem no curso Educação para Jovens e Adultos (EJA) na turma de EJA I, isto é, modalidade dos anos iniciais do ensino fundamental em uma escola no campo situada no assentamento Nova Santo Inácio Ranchinho, no município de Campo Florido, Minas Gerais. Além disso, deve-se enfatizar que já havia intenção de pesquisa pelo processo da IT, uma vez que este se articulava em um trabalho de conclusão de curso e visava, além do objetivo de pesquisa, propiciar a abertura do EJA II na escola junto a outros movimentos sociais articulados a comunidade assentada como o Programa de Educação Tutorial da Universidade Federal 
do Triângulo Mineiro (PET UFTM) - Serviço Social, Movimento Universidade Popular (MUP) a própria Universidade (UFTM), que se consolidou no ano de 2020.

Inspirado na IT freireana, este trabalho foi delineado a partir dos três momentos pedagógicos proposto por Delizoicov, Angotti e Pernambuco (2009), pelos quais culmina os cinco passos descritos por Freire (2015) adaptados para o ensino de ciências em três momentos, sendo eles: levantamento preliminar, codificação-descodificação, redução temática. O quadro a seguir demonstra essa organização nas ações formativas no assentamento.

Quadro 1: etapas e estratégias correspondentes desenvolvidas ao longo do trabalho.

\begin{tabular}{|c|c|c|c|}
\hline Encontro & $\begin{array}{c}\text { Momentos Pedagógicos } \\
\text { correspondentes à fase da } \\
\text { IT } \\
\end{array}$ & Tema & Estratégia \\
\hline I & $\begin{array}{l}\text { Momento Pedagógico 1: } \\
\text { Levantamento Preliminar }\end{array}$ & $\begin{array}{l}\text { A história do assentamento Nova } \\
\text { Santo Inácio Ranchinho }\end{array}$ & Roda de conversa \\
\hline II & $\begin{array}{l}\text { Momento Pedagógico2: } \\
\text { Codificação }\end{array}$ & $\begin{array}{l}\text { Conflitos enfrentados pela } \\
\text { comunidade }\end{array}$ & $\begin{array}{l}\text { Varal de ideias;Árvore do Passado e } \\
\text { Árvore do Futuro }\end{array}$ \\
\hline III & $\begin{array}{l}\text { Momento Pedagógico2: } \\
\text { Descodificação }\end{array}$ & $\begin{array}{l}\text { A ecologia e suas relações com a } \\
\text { produção }\end{array}$ & $\begin{array}{l}\text { Nuvem de palavras: o passado e o } \\
\text { futuro; O que é a praga; Relações } \\
\text { ecológicas; Teia alimentar }\end{array}$ \\
\hline IV & $\begin{array}{l}\text { Momento Pedagógico } \\
\text { 3:Redução temática }\end{array}$ & $\begin{array}{l}\text { Meios de produção para o } \\
\text { assentamento }\end{array}$ & $\begin{array}{l}\text { Identificação de lotes; Calendário de } \\
\text { Produção; Meios de Cultivo }\end{array}$ \\
\hline
\end{tabular}

A fase do levantamento preliminar se deu por uma roda de conversa entre veteranos e novatos que compartilharam suas memórias individuais e familiares, participações na consolidação da comunidade naquele espaço. Dentre as explanações foi apresentada a história da escola, da chegada dos assentados ao município de Campo Florido, assim como dos conflitos e mobilizações que envolveram e permearam os vinte e sete anos do assentamento.

No segundo encontro a estratégia planejada visava à identificação das contradições presentes nas falas dos participantes, para isso foi montado um varal com as ideias e falas que emergiram do primeiro encontro, para que os participantes escolhessem uma das falas e comentassem em grupo, movimentando a discussão com provocações dos mediadores, a fim de identificar as situações limites vivenciadas. Foi proposto a seguir, a construção de uma "árvore do passado" que seria composta por ideias e sentimentos dos participantes com relação a sua história, assim como a história do assentamento e uma "árvore do futuro" na qual os participantes deveriam a construir a partir de seus desejos e expectativas para a comunidade. 
A codificação se inicia a partir das discussões do grupo de pesquisadores/mediadores frente os resultados do segundo encontro, culminando então no planejamento e desenvolvimento das atividades do terceiro encontro. Foram considerados principalmente os elementos mais recorrentes nas discussões trazidos pelos assentados. $\mathrm{O}$ encontro correspondente a esta etapa se deu em três etapas. Em primeiro lugar uma culminância das árvores do passado e futuro em duas nuvens de palavras que evidenciavam os elementos mais frequentes dentre os apontamentos dos participantes. Já mobilizando algumas problemáticas trazidas pelos alunos, foi realizada uma aula expositiva dialogada que tinha como principal tema o equilíbrio ecológico e cadeia alimentar, elementos relacionados ao recorrente ataque de pragas relatado pelos alunos. Na última etapa, foi conduzida uma dinâmica de teia alimentar utilizando de um barbante para conectar os alunos, que durante a prática representavam algum organismo presente no ecossistema em que a comunidade estava inserida - o cerrado.

No quarto e último encontro as questões levantadas ao longo de todo o processo foram mobilizadas pensando a redução dos temas envolvidos na situação limite percebida. A partir das demandas relacionadas ao escoamento da produção, assim como as dificuldades relacionadas à produção propriamente dita foram planejadas as atividades do encontro. Primeiramente foram identificados os lotes no mapa do assentamento visando articular possíveis cooperações entre vizinhos, assim como a proximidade de áreas de preservação e corpos hídricos. Também foi construído junto aos alunos um calendário de produção, representando os períodos do ano e os produtos que poderiam ser fornecidos por cada um nos respectivos períodos. A partir desse quadro, foi realizado um comparativo entre a monocultura, o plantio consorciado e os sistemas agroflorestais numa apresentação dos princípios básicos de cada, acompanhando uma tabela que contemplava os respectivos investimentos, tempo de colheita e lucro de cada sistema de produção.

É importante destacar que em acordo com o referencial freireano utilizado, a cada planejamento era necessária uma busca constante de novas informações e elementos que o grupo não dominava, visto que eram específicas das vivências dos agricultores. Essa busca caracteriza a relação horizontal entre os participantes do processo visto que o conteúdo não está fixado em uma das partes, mas é construído a partir das problematizações de situações que se fazem limitantes (FREIRE, 2015). 
Como instrumentos para a construção dos dados foram utilizados o caderno de campo para registros de observações dos principais momentos de acordo com Restrepo (2018) e ideias do encontro, assim como a gravação em áudio, possibilitando posteriormente a transcrição exata das falas. Além disso, também foram utilizadas as produções escritas de cada encontro, assim como registros fotográficos.

\section{CARACTERIZAÇÃO DA COMUNIDADE NOVA SANTO INÁCIO RANCHINHO}

Num contexto histórico de luta contra a política latifundiária, movimentos sociais se mobilizam em todo território nacional pelo direito à terra, enquanto o governo federal responde pouco favorável através da implementação de assentamentos e desapropriação de terras improdutivas (BERGAMASCO, 1997). Neste cenário, trabalhadores rurais de Limeira D'Oeste se organizaram e ocuparam a fazenda Santo Inácio Ranchinho, localizada no município de Campo Florido, Minas Gerais, até ser reconhecido como assentamento em 1994. A propriedade de 3.583,58 hectares foi dividida em 115 lotes de 25 hectares em média, a comunidade ainda contou com espaços reservados para a construção de escolas e uma área total de 692,69 hectares de reservas naturais conforme a figura abaixo. 

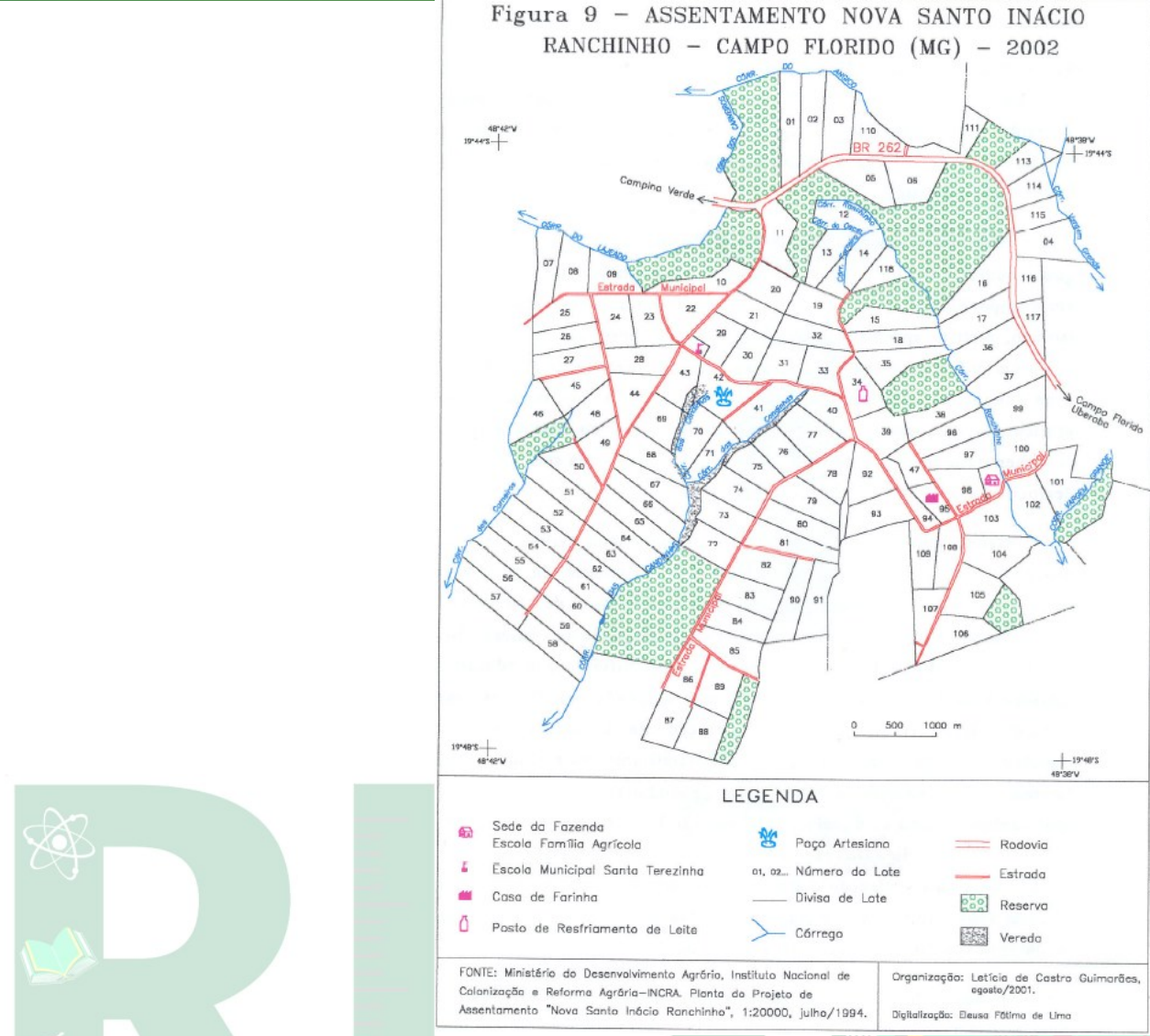

Figura 1. Mapa do loteamento do assentamento. Fonte: GUIMARÃES, 2002.

É importante olhar para o campo como um lugar de trabalho, vida, construção de significados e culturas, e não a partir de uma concepção de sujeitos arcaicos e atrasados como são geralmente caracterizados pelo olhar dos centros urbanos. Diante da exclusão, esses sujeitos se mobilizam em resistências econômicas e culturais através de políticas públicas. A caracterização dos sujeitos do campo se dá pelo modo peculiar de se relacionar com o trabalho, na organização das atividades de produção junto aos membros da família, relações familiares e entre vizinhança priorizadas na cultura e nos valores, celebrações comunitárias da colheita, dentre outros aspectos como a relação, manejo e valor simbólico da natureza (GUIMARÃES, 2002).

As principais atividades econômicas desenvolvidas no assentamento se concentram na produção de hortaliças, leite, aves e ovos e uma parcela significativa da comunidade presta serviços para uma usina sucroalcooleira que faz divisa direta com o assentamento. Essa movimentação caracteriza uma importante contradição vivenciada na comunidade, uma vez que se opõe aos princípios dos movimentos sociais de reforma agrária. Além disso, se constitui como uma situação limite, pois configura o que Toledo 
e Barrera-Bassols (2015) denominam amnésia biocultural, uma posição de desmobilização e silenciamento de saberes e modos de ser e estar no mundo que são subjugados em nome de tecnologias e saberes científicos, considerados universais a partir da perspectiva moderna. Os parágrafos a seguir descrevem o contexto da investigação a partir do qual os enunciados serão analisados por uma abordagem qualitativa exploratória dos fenômenos em foco em uma tipologia da pesquisa-ação (TOLEDO; JACOBI, 2013).

As atividades relatadas neste trabalho aconteceram na escola Municipal Santa Terezinha, um símbolo muito importante no assentamento, pois marca a consolidação e pertencimento da comunidade naquele espaço. Essa simbologia se dá a partir da movimentação coletiva dos assentados frente ao poder público municipal pela garantia da educação como um direito básico, posteriormente essa mobilização resultou na construção do prédio pela própria comunidade, estabelecendo uma relação ainda mais próxima com a escola. A partir daí a escola passa a ser não somente um marco no assentamento, mas a constituir um papel de alta importância na comunidade visto que garantia a formação escolar das crianças e jovens assentados, e atualmente também a formação de jovens e adultos, contemplando veteranos de acampamento e lideranças políticas.

Dentre os participantes da pesquisa, serão usados pseudônimos garantindo o anonimato das identidades dos participantes. José e Ana são assentados membros de uma família importante na constituição política do assentamento, visto que são sujeitos que estão mobilizados desde o início da organização para a conquista da propriedade. Ana, José, João, Julia, entre outros membros constituem um grupo que buscam por alternativas de produção e cultivo viáveis e que proporcionarão uma nova condição econômica a eles. João por sua vez, também é uma figura forte politicamente na comunidade, que juntamente com Júlio fomentam discussões acerca das produções do grupo e comunidade como um todo, evidenciando o quanto as questões econômicas e relacionadas às produções mobilizam os alunos da EJA.

Além dos alunos que compõe grupos já mencionados, Pedro é um estudante que possui uma relação extremamente forte coma escola, pois, fez parte da construção do prédio no qual seus filhos passaram pela alfabetização e formação e retorna agora para se alfabetizar, após a perda de um dos filhos. Dona Julia é uma aluna assídua da escola, esteve presente em todas as aulas programadas e sempre se mostrou muito receptiva as 
atividades propostas pelo grupo. Assim, pode-se perceber que a turma participante do trabalho é bastante heterogênea, com histórias e papéis distintos, os alunos da EJA e outras figuras que fazem parte do contexto da escola, constituem um grupo experiente na luta pela terra e que procuram meios para enfrentar os conflitos que se fazem presente para todos.

\section{RESULTADOS E DISCUSSÕES}

A partir da IT freireana como modelo teórico metodológico que orientou os processos de conhecimento, planejamento, ações e reflexões apresentados anteriormente nesta pesquisa, os resultados apresentados serão descritos e analisados a partir das três frentes vivenciadas: a) Imersão na realidade do Assentamento Santo Inácio Ranchinho: fase preliminar da investigação temática; b) O planejamento pela codificação dos conflitos: problematizando a decodificação pelo ensino de ciências; c) Redução de temas pela dialogicidade: as interações pelos processos de aprendizagem em ciências.

\section{A imersão na realidade do Assentamento Nova Santo Inácio Ranchinho: fase preliminar da investigação temática}

Durante os dois primeiros encontros, o olhar foi direcionado a uma aproximação da comunidade e reconhecimento das vivências dos assentados. A partir da roda de conversas conduzida no primeiro, foi possível conhecer a história individual de alguns alunos que participaram da mobilização inicial, de sujeitos de grande representação nessa mobilização. As falas apresentavam histórias de superação, de força e de luta, o aspecto do pertencimento, da identidade de homens e mulheres do campo era comum a todos evidenciando a identidade de camponês como autorreconhecimento, e não uma denominação externa por estereótipos (GUIMARÃES, 2002).

Ao longo das discussões realizadas na roda de conversa, o reconhecimento na condição de sujeitos do campo pelos próprios participantes levou as falas para apontamentos de problemáticas do assentamento que eram sentidas tanto pela comunidade de modo coletivo, como por cada assentado individualmente. As questões relacionadas à produção eram uma demanda presente na fala de todos os assentados, nos diversos aspectos que atravessam o processo do cultivo do alimento até a venda do 
produto. Foram colocados aspectos desde o preparo do solo, o preço de insumos e sementes, ao tratamento de pragas, dentre outros gastos que, ao final das contas, não conseguiam ser supridos pela produção. Ao final do dia foi possível conhecer o lote de Ana, uma das participantes que produz juntamente com seus filhos diversas hortaliças.

No segundo encontro, ainda ligado à fase de levantamento preliminar, mas visando identificar situações limites, foi possível discutir algumas falas da primeira aula de maneira mais aprofundada. Uma das falas de Pedro, utilizadas para discussão foi " $E$ mais barato comprar o arroz do que produzir", ainda remetendo ao contexto da monocultura e a sua naturalização, configurando uma relação de opressão e silenciamento em comparação com meios de cultivo tradicionais. Durante a discussão, o aluno levantou o seguinte argumento:

"Hoje é muito difícil, você vai, por exemplo, quando chegamos pra cá, eu produzia todo ano eu plantava arroz. Colhia 30 a 40 sacos de arroz. Mas cê não precisava por adubo, a gente fazia manualmente, hoje em dia é tudo compro e as vezes, não, com certeza o adubo que custava 10, hoje é 100 sabe? E pra você produzir hoje nesse solo é muito mais caro...".

Nesse sentido, percebe-se que o modo de produção utilizado no assentamento demanda, além da mão de obra deles próprios, investimentos em insumos químicos para adubação do solo e tratamento de pragas, beneficiamento entre outros. Os quais são também investimentos realizados por grandes produtores, que tem como mercado principalmente a exportação, tendo a tecnologia como produção da ciência que reverbera em desigualdades em prol do econômico. Tal fato contribui reduzindo não apenas recursos naturais, mas linguagens e conhecimentos (TOLEDO; BARRERABASSOLS, 2015).

Assim, identifica-se uma forte contradição vivenciada no assentamento, embora ele seja oriundo de uma mobilização pela reforma agrária, pelo direito a subsistência pela agricultura familiar, os produtores possuem como parâmetro a produção em larga escala, que além de negar sua maneira de se relacionar com a terra são inviáveis em recursos financeiros e humanos necessários. As fronteiras próximas com a usina sucroalcooleira e com as monoculturas estão oprimindo geográfica e culturalmente a comunidade do assentamento, pela imposição do modelo de produção exploratório, negando a possibilidade de uma relação existencial e de uma produção harmônica com o ambiente. 
Essas questões expressas representam sistemas de opressões (FREIRE, 2015) vividos que mecanizam formas de vida dentro de um parâmetro normalizado e tido como "evoluído", que foi materializado principalmente pelo olhar desenvolvimentista dos centros urbanos e as características ditas tecnológicas disponibilizadas neles (TOLEDO; BARRERA-BASSOLS, 2015). Há, portanto, uma racionalidade, razão e formas de pensar e conceber essas relações de ser e estar no mundo no sentido de progresso, mas que ao mesmo tempo, impõe lógicas de vida. Nesse processo, o campo e as tecnologias utilizadas ali muito antes da instituição da ciência moderna são descartáveis, e substituídas por tecnologias que, muitas das vezes, otimizam processos visando lucros sem pensar na relação insustentável dos territórios, seus recursos naturais e simbólicos. A tensão entre essas relações evidencia coerções e silenciamentos por um mecanismo dominante e opressor e que se faz como limite para alguns grupos socioculturais, ou seja, ou incorpora esse formato ou é marginalizado (FREIRE, 2015).

Essa relação é ainda observada pelas palavras que foram expressas e que afetam a realidade desse assentamento durante os registros das expectativas e perspectivas pelas quais os participantes olhavam e construíam uma árvore simbólica com elementos do passado e para o futuro. As nuvens foram geradas de acordo com a frequência que as palavras apareciam, sendo que as palavras mais frequentes têm maior destaque na representação gráfica.

Na nuvem do passado as palavras com maior destaque foram "Coletividade", "Mobilização" e "Lutas", o que mostra a união e organização enquanto coletivo que eram demandados no processo de conquista da terra. Por outro lado, na nuvem do futuro as palavras que apareceram com mais frequência foram "Identidade", "Coletividade" e "Produção", que remetem a uma desmobilização em que a comunidade se encontra atualmente, ocasionada pelas questões produtivas vivenciadas no assentamento. 

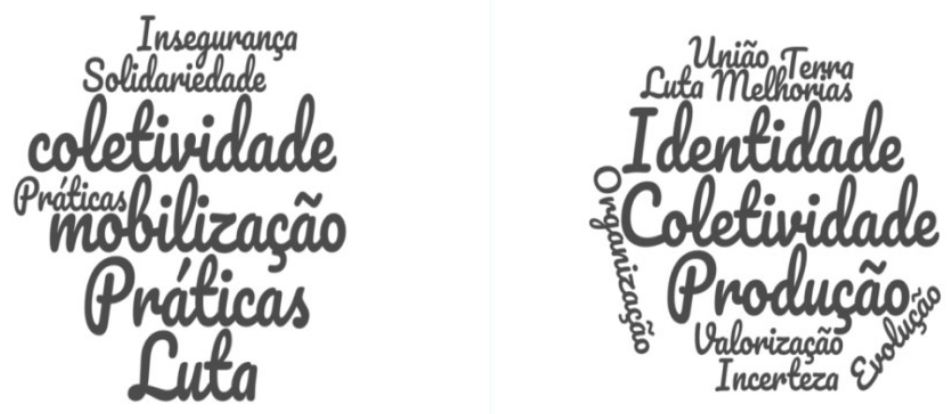

Figura 2Nuvens de palavras, produção autoral pelo site Word Clouds. Disponível em: $<$ https://www.wordclouds.com/ $>$

A partir da análise é possível perceber palavras em que sentidos provindos dessa relação coletiva, mobilizada por movimentos sociais e uma horizontalidade de pensar as formas de ser e estar no mundo pela relação com o território. É exprimido que o passado do assentamento foi permeado por uma forte mobilização dos agricultores pela garantia do direito à terra, num contexto de incertezas em que a Coletividade, assim como a Solidariedade e Luta eram princípios fundamentais da organização da comunidade, e são destaque na representação. Também por meio das discussões anteriores ao registro da percepção dos participantes, a fala de alguns agricultores demarca uma produção independente de insumos e em equilíbrio com o ambiente, uma vez que seguiam de acordo com estações e períodos específicos para plantio e colheita.

Ao olhar para a nuvem do futuro, as palavras Identidade, Coletividade e Produção possuem grande destaque. Sendo a nuvem do futuro um horizonte vislumbrado pelos participantes, é possível inferir uma desmobilização dos agricultores em sua organização, influenciado pela imposição de um modo de produzir, ser e estar no mundo que fixa a comunidade do campo num lugar arcaico, ultrapassado e de subalternização pelo o modelo hegemônico dominante representado pela usina que adota a monocultura. Essa subalternização se dá pela fragilização do sentimento de pertença e da identidade campesina, caracterizando o processo de apagamento que promove a amnésia biocultural e, o sentido da coletividade pode ser um horizonte para a busca da memória que foi soterrada pelas imposições dominantes (TOLEDO; BARRERA-BASSOLS, 2015). 


\section{O planejamento pela codificação dos conflitos: problematizando a decodificação} pelo ensino de ciências

No terceiro encontro, tendo como premissa as fases e codificação e descodificação, tinha como perspectiva a problematização dos elementos envolvidos na situação limite: A produção pela agricultura de base familiar frente os impactos e opressões advindos da agroindústria. O desenvolvimento da dinâmica muitas vezes enfrentou certa resistência dos alunos, algumas falas como "Já sabemos isso...", "O nosso problema é com relação ao mercado" ou ainda "O que precisamos é definir metase fechar parcerias..." foram recorrentes durante a atividade. Essa resistência evidencia a importância da mediação do conhecimento escolar frente às demandas dos alunos e a partir de sua realidade, de modo que o currículo não seja uma imposição baseada em memorização e reprodução, mas que emerja de questionamentos dos alunos,subsidiando a reflexão, a compreensão e a transformação social(FREIRE, 2015). Além disso, a utilização das terminologias relacionadas a questão do mercado demarcam a influência da lógica capitalista para a organização do pensamento dos agricultores, evidenciando o processo de silenciamento dos saberes campesino em detrimento de um modelo hegemônico dominante.

Embora apresentassem alguma resistência, os alunos se mantiveram na atividade e ao longo da mesma, indicaram reflexões sobre a conjuntura vivenciada ali, como demarca a fala de João: "Nós precisamos fazer o que o agronegócio não faz, se insistirmos em fazer a mesma coisa já começamos perdendo”. Essa fala marca a desestabilização de uma racionalidade naturalizada, não fixando o agricultor em uma posição desfavorecida, por outro lado, alguns elementos que despertam para a amnésia promovida pelo sistema do qual se reproduzem as premissas são observadas. Esse deslocamento já sinaliza uma mudança de enunciados que antes reverberava em prol de um parâmetro desenvolvimentista, pró-capitalista, neoliberal ${ }^{1}$ e que começa se perceber enquanto silenciado, oprimido, dentro deste sistema.

Assim, a memória seria um elemento que não permite a conversão e submissão a esse sistema, pois é nesta lógica que se encontram escravizados e subalternizados ao grande produtor, que adota a prática exploratória e é detentor dos recursos tecnológicos.

1 Desvincula responsabilidade ao Estado em prol de um individualismo, políticas sociais mínimas de proteção, ressaltando uma ideologia meritocrática. 
Partindo do processo educativo, as estruturas mantenedoras do estado de amnésia foram tensionadas, provocando o questionamento e reflexão, numa formação que se dá pela experiência e sensibilização.

Por outro lado, essa fala não evidencia uma tomada de consciência total dos alunos, mas a emergência de elementos silenciados pela amnésia biocultural que passam por uma reflexão a partir dos tópicos discutidos na aula. Numa aula que partisse da concepção bancária, o currículo estaria "viciado", não considerando estes elementos silenciados e, portanto, se mantendo no eixo da epistemologia da ciência moderna, compactuando com os discursos hegemônicos mesmos que propiciam a amnésia biocultural. Dessa maneira, através da estruturação do currículo escolar, essa hegemonia se sobrepõe em detrimento aos saberes provenientes de povos originários, relações sociais estabelecidas por meio de diferentes racionalidades (DUTRA; CASTRO; MONTEIRO, 2019).

Em resposta a um viés neoliberal e mercantilizado que rege a escola, essa abordagem propõe, pela dialogicidade, uma educação que vê no ensino de ciências a possibilidade para superação de seus conflitos sociais a partir dos conflitos utilizando para compreender a situação existencial daquela comunidade campesina (FREIRE, 2015; DELIZOICOV; ANGOTTI; PERNAMBUCO,2009).

No intervalo entre o encontro de número III e IV, a partir do exercício de reflexão propostoe influenciado pela pedagogia da alternância, os alunos retomaram, a partir de discussões, ideias discutidas em grupo, os elementos mobilizados na fase de codificação, resultando no consenso registrado na figura 3 .

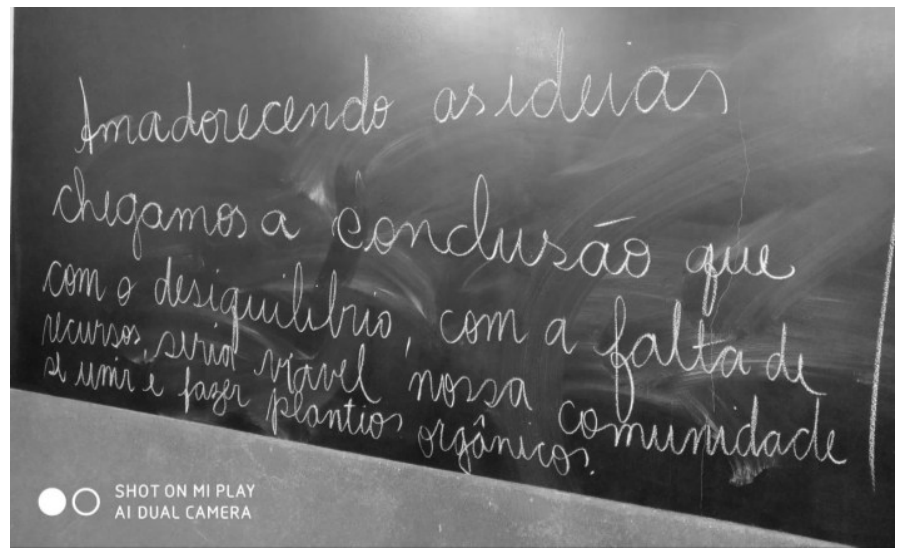

Figura 3. Momento chave da descodificação Imagem que ilustra os alunos percebendo suas contradições e repensando sua relação com a produção. Fonte: acevo pessoal da professora Luciana (regente da turma). 
A reflexão registrada na imagem reforça o despertar dos alunos participantes para saberes construídos a partir da lida com a terra que estavam sendo silenciados ao passo que, os valores e pressupostos da agroindústria avançavam na comunidade. Não se trata, portanto, de um resgate total de memórias, mas traz em si elementos que contribuem para pensar uma retomada e emancipação pela relação biocultural.

Dessa maneira, a redução temática parte de um olhar para essa relação opressora fazendo inferências para o ensino de ciências a partir dela. Assim, os saberes escolares não se fazem um fim que justifica a seleção de conteúdos, mas um meio pelo qual se compreende as situações de conflitos vivenciadas. A análise desse dado evidencia no processo de pesquisa, portanto, o exercício dialógico dos estudantes pela reflexão e construção de conhecimento a partir da territorialidade (e suas demandas) bem como os conteúdos trabalhados nos encontros.

Redução de temas pela dialogicidade: as interações pelos processos de aprendizagem em ciências

As ciências naturais têm como princípio estudar a natureza e suas relações, produzindo avanços, compreensões dos ciclos da matéria, da vida e, portanto, sobre processos nos quais os seres humanos também estão implicados (BRASIL,2017). Dessa maneira, o universo temático frente às competências dessa área do conhecimento se constitui pelos processos mencionados, a partir do conflito socioambiental que se estabelece entre a agricultura de base familiar e o agronegócio.Evidenciando elementos silenciados pela amnésia biocultural em nome de um meio de produção exploratório guiado pela geração do capital.

A emergência destes elementos ao longo de uma discussão de conceitos da ciência escolar evidenciou a relação de resposta entre o ensino de ciências e o despertar para essa amnésia, frente a memória biocultural, propiciada pelo conflito. Isto é, o ensino de ciências da natureza enquanto uma linguagem que explica o mundo natural, que inclina-se para desenvolvimentos de habilidades sobre fenômenos e elementos, constituições da natureza (CHASSOT, 2003) e que para além dessas relações mais conceituais e estruturais, estabelece diferentes compreensões de mundo, impulsionando resoluções de problemas na sua interface social (DELIZOICOV; ANGOTTI; 
PERNAMBUCO, 2009) não estão distanciadas das relações mais emergentes expressadas por esses sujeitos. Situações que são existenciais, por palavras Freireanas, a respeito das tensões acerca de modos de leitura de mundo bem como as opressões a partir dessas diferentes condições, que nesse caso fica evidente frente aos sentidos dado à terra, ao território e a vida a partir desse lugar, que além de geográfico carrega memórias e identidades de sujeitos e diferentes formas de ser e estar no mundo.

Frente a essas interpretações, ações foram pensadas de acordo com os temas geradores observados até o momento conforme indica a figura 4. A apresentação de meios alternativos de cultivo reforça alguns conteúdos de ciência que já apareceram em aulas anteriores e outros novos, também emergentes do universo temático dos conflitos socioambientais vividos pela comunidade e que são necessários para iluminar as questões que bloqueiam o assentado e reforçam o apagamento dos traços de sua identidade.

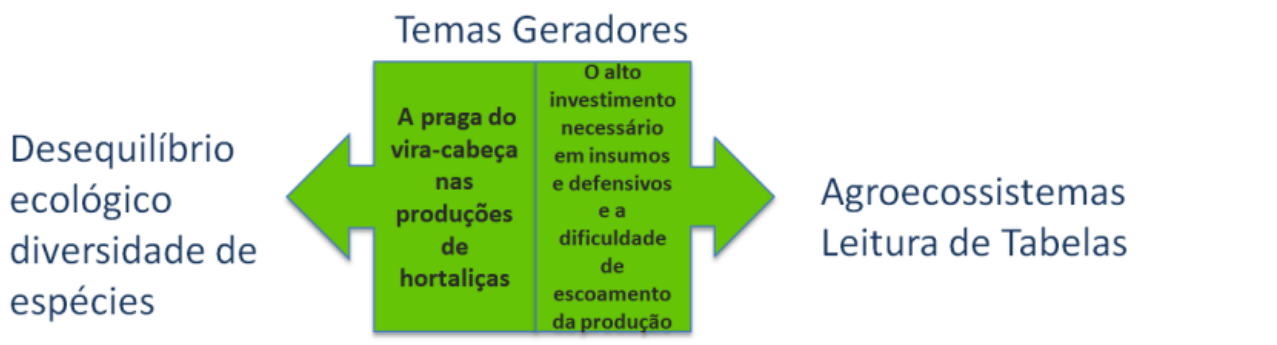

Figura 4. Representação dos temas geradores a partir do universo temático. Produção autoral.

Ao discutir esses aspectos que estavam envolvidos pela amnésia biocultural, foi colocada em questão a relação com a terra e com a natureza, pela qual se mobilizaram no tempo passado em busca da conquista do direito da terra. Assim, iniciou-se um despertar para esse apagamento e uma busca pela memória que outrora possibilitou a permanência no campo, a governança participativa, a cooperação coletiva, dentre outras relações próprias que demarcam a identidade campesina, pela qual os agricultores e agricultoras fortemente se afirmam. 
Nesse sentido, baseando-se no mapa do loteamento conforme a figura $1 \mathrm{e}$ observando os fragmentos de mata presentes no assentamento, foram discutidos sistemas de plantio consorciado, sistemas agroflorestais e os benefícios relacionados a serviços ambientais prestados que esses meios trariam como também relacionados às atividades econômicas, geração de empregos e novas oportunidades para a comunidade.

Partindo da reflexão acerca da situação limite que se configura pelos conflitos vivenciados no assentamento, os participantes se mobilizaram em função de uma reflexão coletiva e individual dos aspectos em disputa, promovendo um deslocamento de enunciados impostos anteriormente que contradiziam o princípio fundamentador da organização da comunidade: a governança participativa que pela coletividade garante a permanecia no campo assim como a defende a identidade e o pertencimento de homens e mulheres do campo no campo. Assim, colocando em questão os parâmetros estabelecidos para a produção, pensando a partir da realidade da agricultura de base familiar. Nessa perspectiva observa-se um exercício pela memória biocultural dos saberes da comunidade ancestral frente à necessidade de se produzir em harmonia com os ciclos naturais visando à permanência no campo e a afirmação da identidade campesina.

\section{CONSIDERAÇÕES FINAIS}

O relato dessa pesquisa, a qual conta com vivências pedagógicas orientadas por uma intencionalidade de pesquisa em educação, sobretudo acerca da educação para e/ou frente a realidade do campo, tem sua base no modelo teórico-metodológico da investigação temática. Para tanto, foi possível observar e analisar pontos máximos do processo de ensino e de aprendizagem pela abordagem freireana. Após o reconhecimento da comunidade e seu contexto, da história dos sujeitos participantes da atividade foi possível identificar conflitos socioambientais que resultam no apagamento da memória da comunidade em termos de produção e relação com a terra como meio de subsistência, caracterizando a amnésia biocultural.

A resistência observada ao abordar as questões relacionadas ao plantio é fruto de uma percepção de que o sucesso está relacionado à ideologia capitalista de que se deve produzir em função do mercado sob qualquer justificativa. Por outro lado, sustentar suas atividades produtivas de acordo com as condições ambientais referentes à localidade 
pertencida agregará valores, ambientais e sociais que seriam desprezados em detrimento de valores apenas econômicos.

Por isso a transformação de enunciados próprios da ideologia capitalista como "metas" e "mercado" para a ideia de coletividade é de suma importância para demarcar o momento da codificação-decodificação. Essa percepção impacta de tal maneira que, mesmo vivenciando conflitos políticos internos no grupo, ressignificam a coletividade e cooperação já fragilizadas ainda que por diferentes perspectivas ao perceber a contradição vivida, pois percebem que o trabalho coletivo é fundamental na superação da situação limite, e um caminho possível talvez seja por meio de produções agroflorestais de cadeias curtas.

A partir dos temas geradores das situações limite da comunidade do assentamento foi possível mobilizar conceitos científicos das áreas das ciências naturais deslocando o currículo para um meio para o qual se pode usar para interpretar a sua realidade e transformá-la. Possibilitando assim ressignificar o papel da escola e também da universidade como mediadores implicados que a partir da vivência junto à comunidade percebem as situações limites que atravessam a si mesmos e a instituição, chegando juntos aos temas geradores. Nesse sentido, a pesquisa contribui para ressaltar um potencial destas instituições do campo, principalmente a escola do campo, como fomentadoras de uma governança participativa e da organização do trabalho, transformando a organização da ecologia política local a partir da ação pela investigação temática.

\section{REFERÊNCIAS}

BARBOSA, A. . T.; FERREIRA, G. L.; KATO, D. S. O ensino remoto emergencial de Ciências e Biologia em tempos de pandemia: com a palavra as professoras da Regional 4 da Sbenbio (MG/GO/TO/DF). Revista de Ensino de Biologia da SBEnBio, [S. 1.], v. 13, n. 2, p. 379-399, 2020. DOI: 10.46667/renbio.v13i2.396. Disponível em: http://sbenbio.journals.com.br/index.php/sbenbio/article/view/396. Acesso em: 21 out. 2020.

BERGAMASCO, S. Ma. P. P. A realidade dos assentamentos rurais por detrás dos números. Estudos Avançados, São Paulo, v. 11, ed. 31, p. 37-49, Set./Dez. 1997. Disponível em:http://www.scielo.br/scielo.php?script=sci_arttext\&pid=S010340141997000300003. Acesso em: 25 set. 2019.

BRASIL. Base Nacional Comum Curricular: Educação Infantil e Ensino Fundamental. Brasília: MEC/Secretaria de Educação Básica, 2017. Disponível em: http://basenacionalcomum.mec.gov.br/. Acesso em: Jan./ 2019. 
DELIZOICOV, D.; ANGOTTI, J. A.; PERNAMBUCO, M. M.. Ensino de Ciências Fundamentos e Métodos. São Paulo: Cortez Editora, 2009.

DUTRA, D. S. A.; CASTRO, D. J. F. de A; MONTEIRO, B. A. P.. Educação em Ciências e Decolonialidade: Em busca de Caminhos Outros. In: MONTEIRO, Bruno Andrade Pinto; DUTRA, Debora Santos de Andrade; CASSIANI, Suzani; SÁNCHEZ, Celso; OLIVEIRA, Roberto D. V. L. Decolonialidades na Educação em Ciências. 1. ed. São Paulo: Livraria da Física, 2019. cap. 1, p. 02-17. E-book 16 p.

FREIRE, P. Pedagogia do Oprimido. Rio de Janeiro: Paz e terra, 2015.

GUIMARÃES, L. de C.. Novo Território Em Construção. In: GUIMARÃES, Letícia de Castro. LUTA PELA TERRA, CIDADANIA E NOVO TERRITÓRIO EM CONSTRUÇÃO: o caso da Fazenda Nova Santo Inácio Ranchinho, Campo FloridoMG (1989 - 2001). 2002. Dissertação (Mestrado em Geografia) - Instituto de Geografia, Universidade Federal de Uberlândia, [S. l.], 2002. p. 178. E-book (178 p.).

OLIVEIRA, C. L. de. Um apanhado teórico-conceitual sobre a pesquisa qualitativa: tipos, técnicas e características. Revista Travessias, Cascavel, v. 2, n. 3, p. 12-13, 2008.

RESTREPO, E. Etnografía: alcances, técnicas y éticas. Bogotá: Envión Editores, 2018.

SANTOS, M. de J. dos. A Dialogicidade no pensamento de Paulo Freire e de Hans Georg Gadamer e implicações na cultura escolar brasileira. Cadernos do PET Filosofia, $[s$. l.], v. 5, n. 10, p. 01-11, Jul./Dez. 2014. Disponível em: https://revistas.ufpi.br/index.php/pet/article/view/3271. Acesso em: 30 set. 2019.

SILVEIRA DA ROSA, S..; ROBAINA, J. O Ensino de Ciências nas Escolas do Campo a partir da análise da produção acadêmica. Revista InsignareScientia - RIS, v. 3, n. 2, p. $156-175,24$ ago. 2020.

TOLEDO, R. F.; JACOBI, P. R. Pesquisa-ação e educação: compartilhando princípios na construção de conhecimentos e no fortalecimento comunitário para o enfrentamento de problemas. Educ. Soc., Campinas, v. 34, n. 122, p. 155-173, Mar. 2013.

TOLEDO, V. M.; BARRERA-BASSOLS, N. A Memória Biocultural: A importância ecológica das sabedorias tradicionais. $1^{a}$ Ed. São Paulo: Expressão Popular, 2015. 